\title{
Fabrication of Malachite with a Hierarchical Sphere-like Architecture
}

\author{
Jiasheng $\mathrm{Xu}$ and Dongfeng Xue \\ State Key Laboratory of Fine Chemicals, Department of Materials Science and Chemical \\ Engineering, School of Chemical Engineering, Dalian University of Technology, 158 Zhongshan \\ Road, Dalian 116012, P. R. China \\ *Corresponding author.E-mail: dfxue@chem.dlut.edu.cn
}

\section{Supporting information}




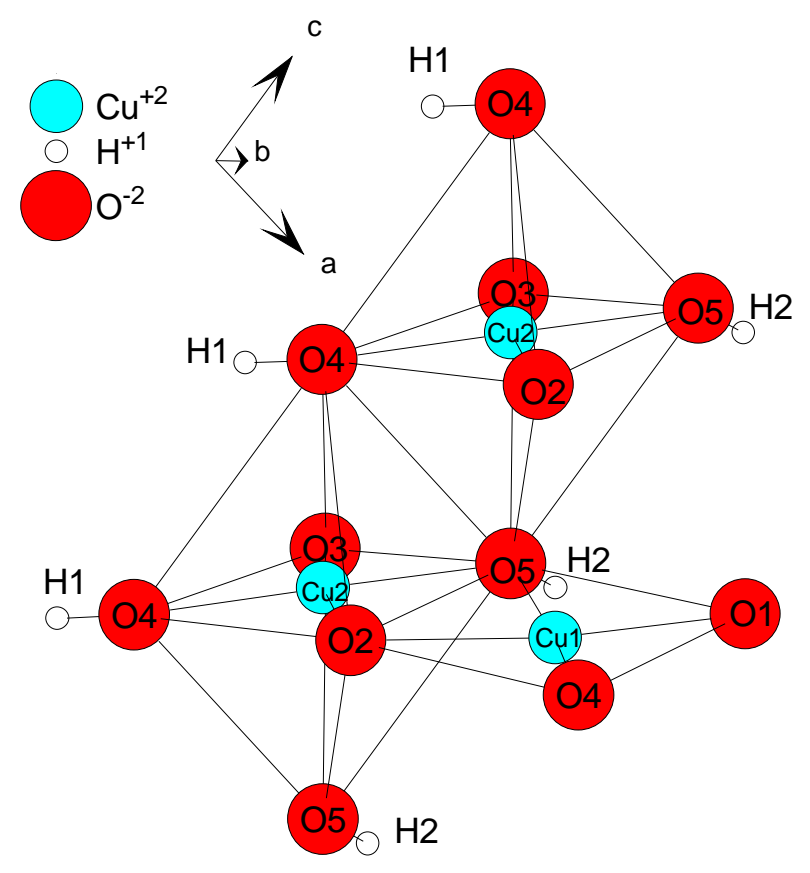

Figure S1. Part of the crystal structure of malachite $\left(\mathrm{Cu}_{2}(\mathrm{OH})_{2} \mathrm{CO}_{3}\right)$, omitting the carbonate oxygen atoms. 


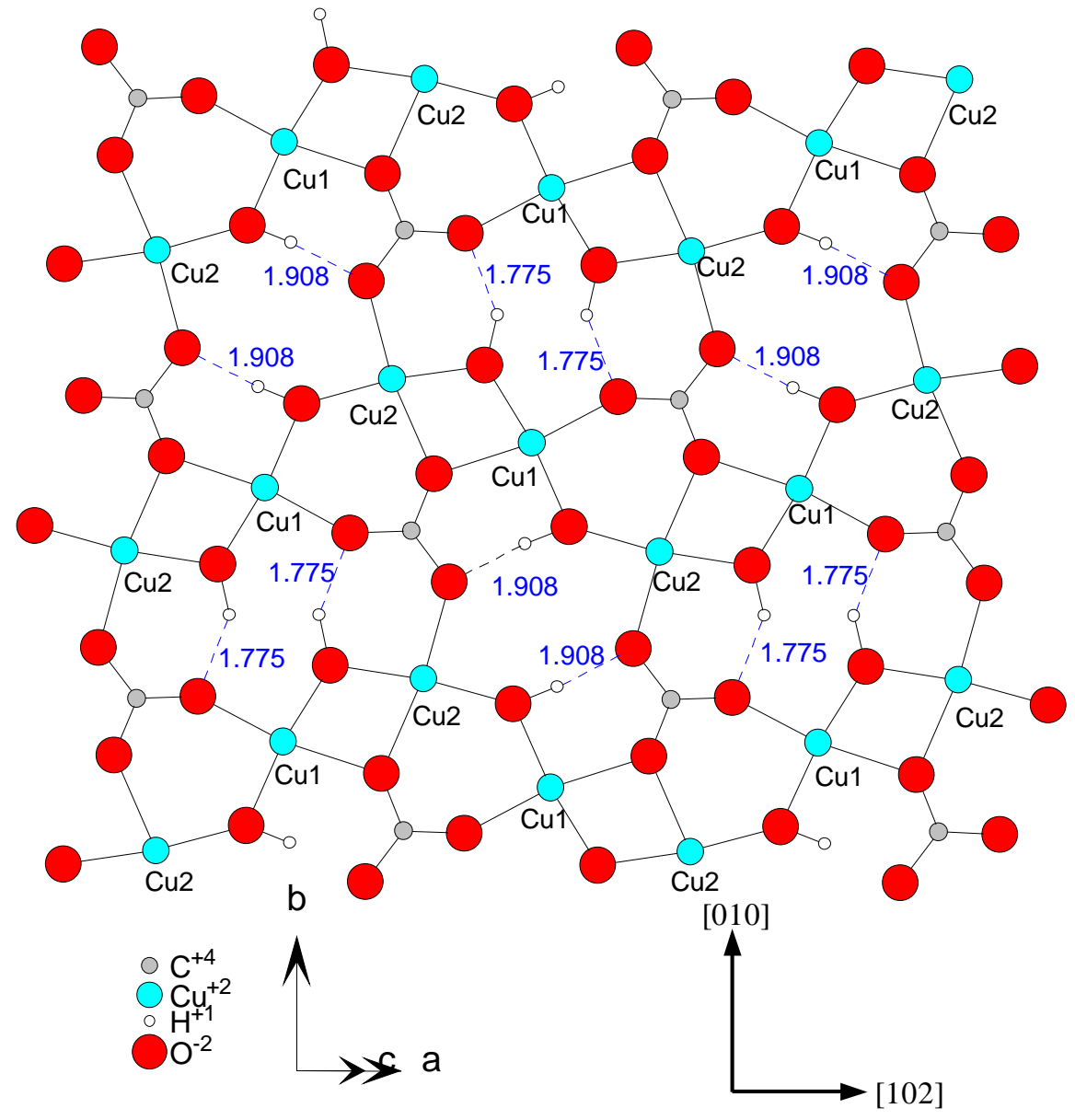

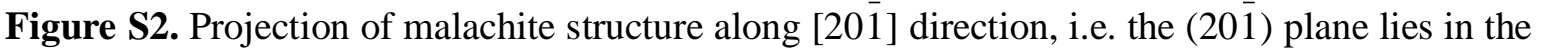
plane of the paper. Dashed lines represent two kinds of hydrogen bonds with the length of 1.775 and $1.908 \AA$, respectively. 


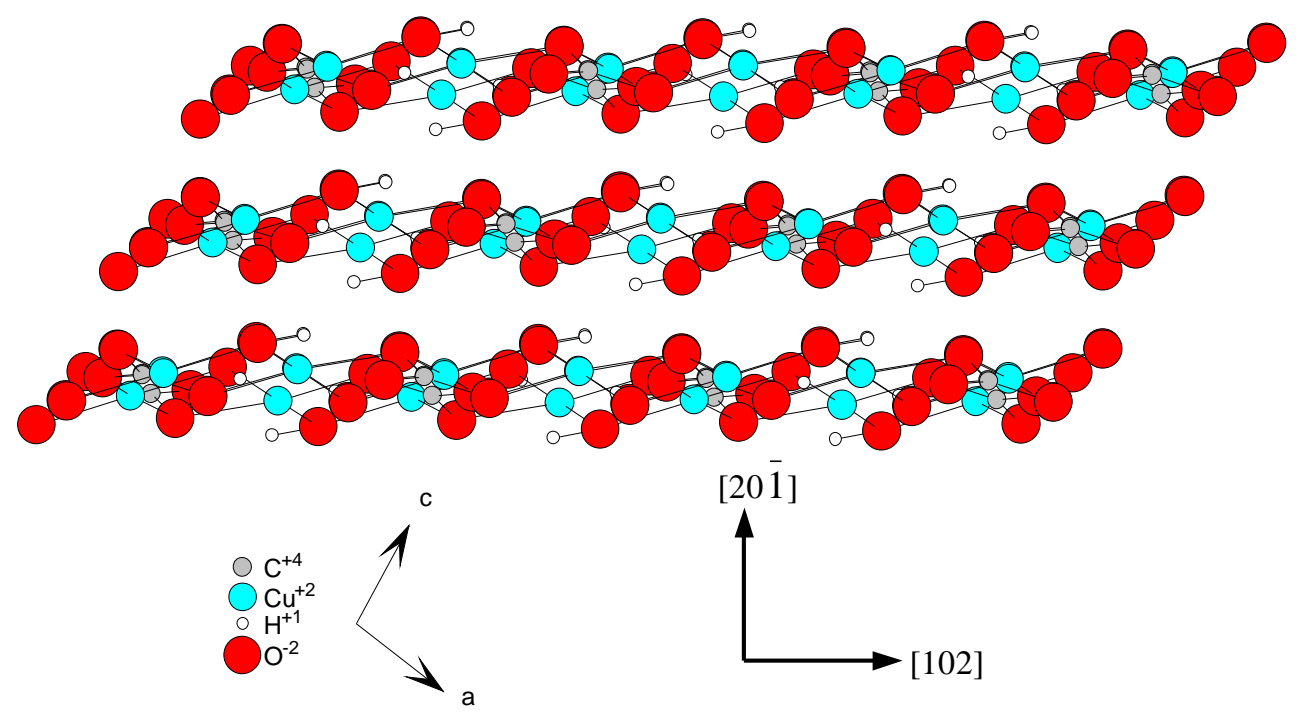

Figure S3. Projection of malachite structure along $b$-axis, i.e. the (010) plane lies in the plane of the paper. 


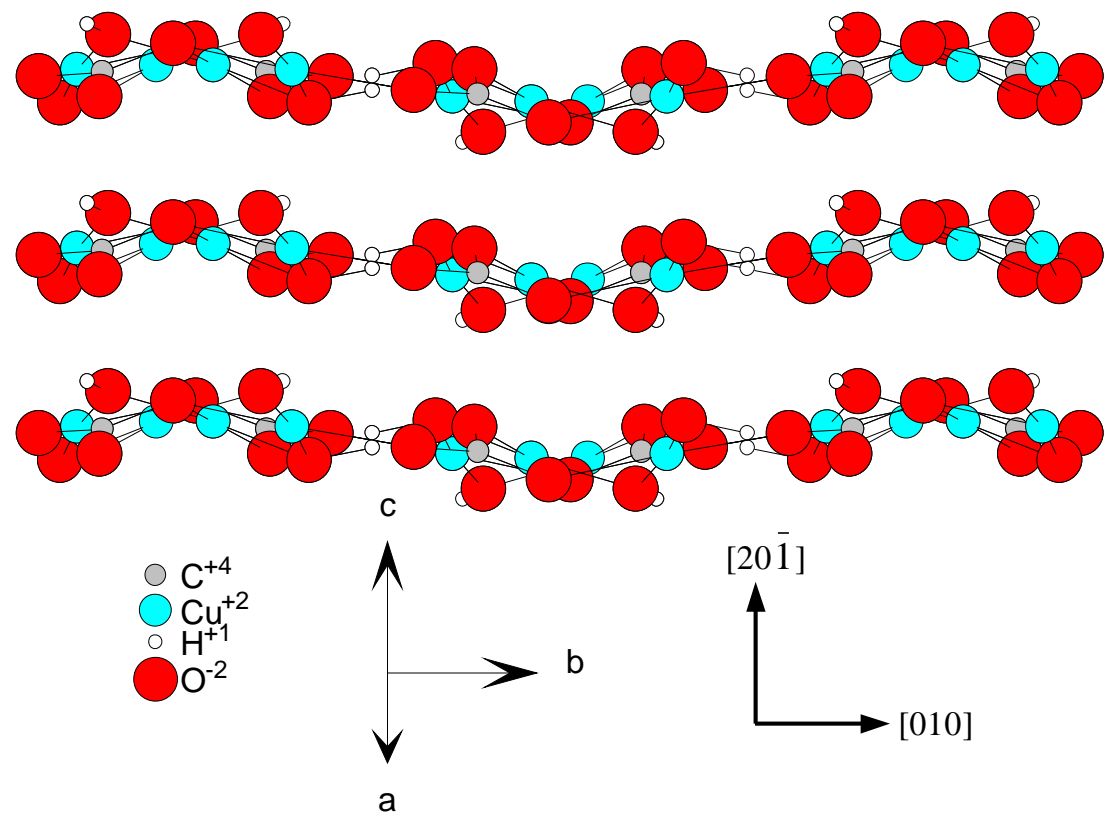

Figure S4. Projection of malachite structure along [102] direction, i.e. the (102) plane lies in the plane of the paper. 


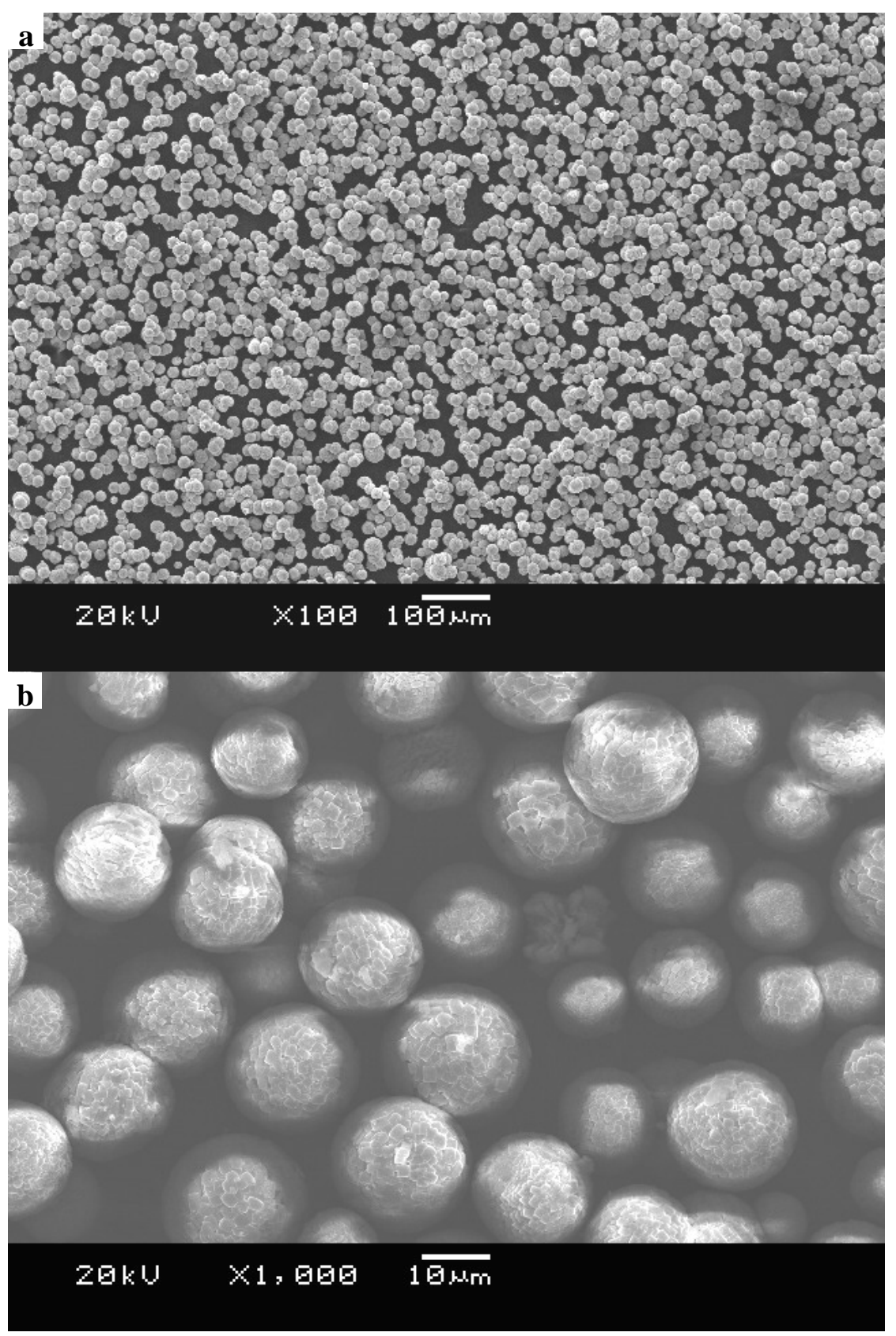



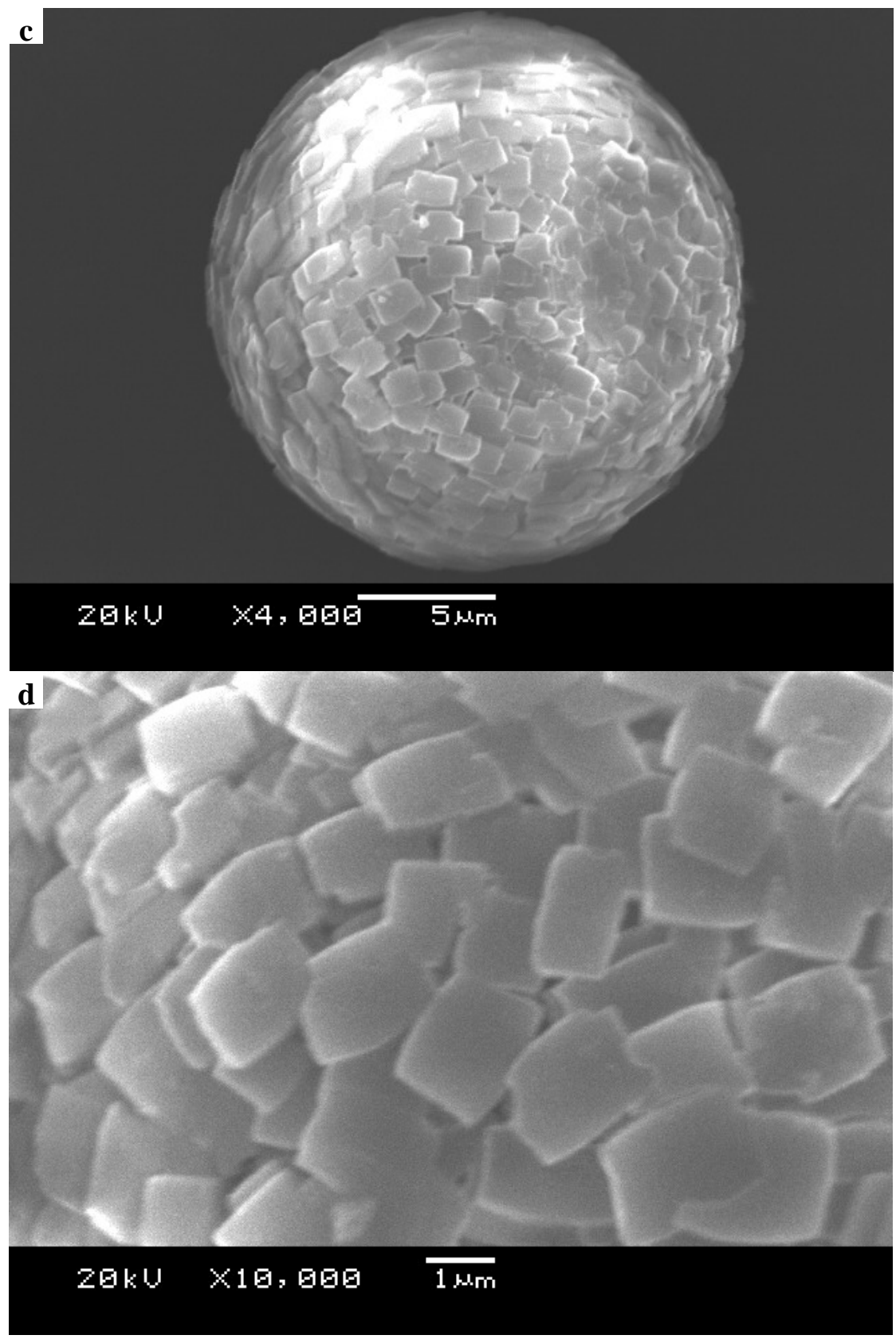


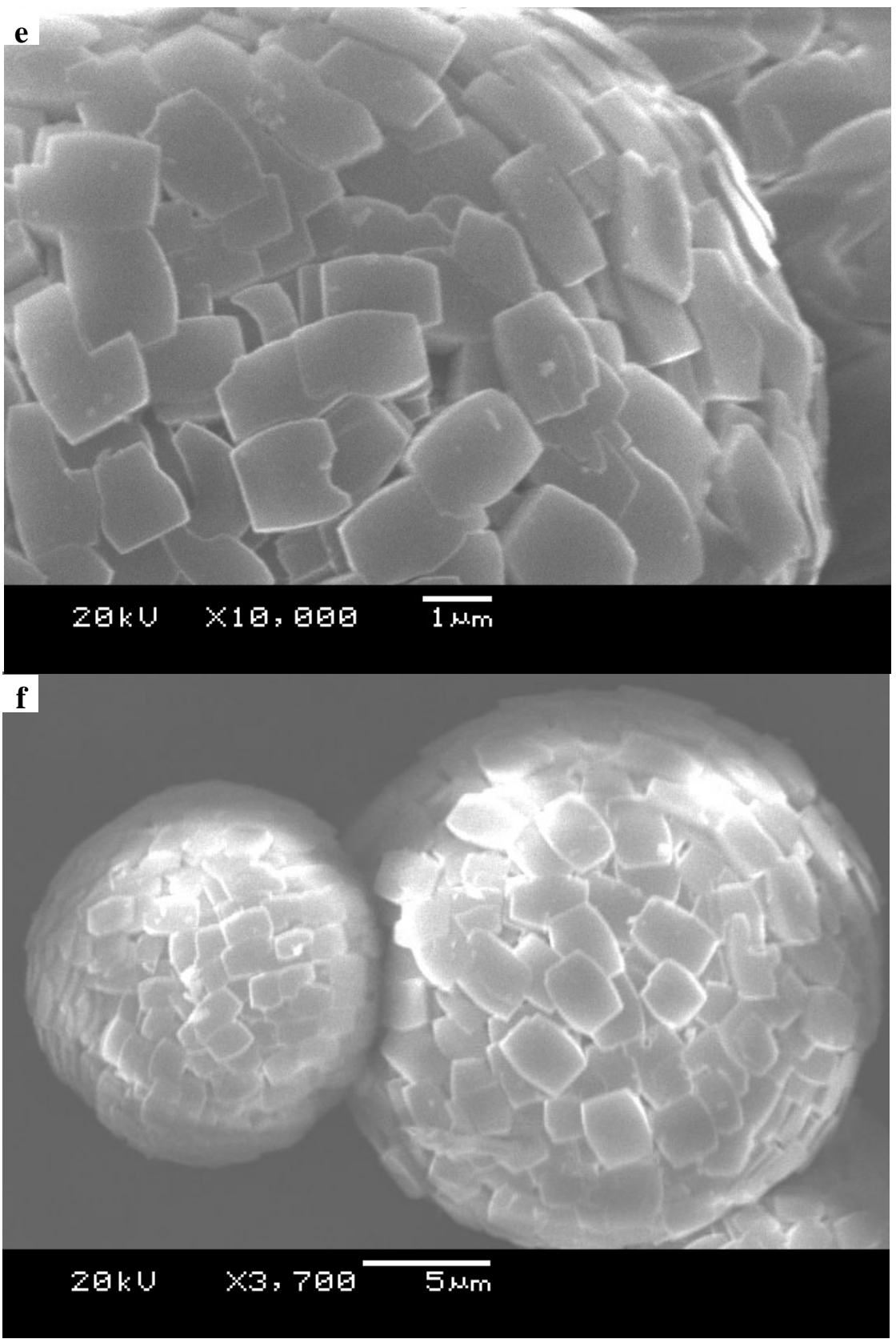

Figure S5. SEM images of malachite hierarchical architecture prepared at $110^{\circ} \mathrm{C}$ and $12 \mathrm{~h}$, with different magnifications. 


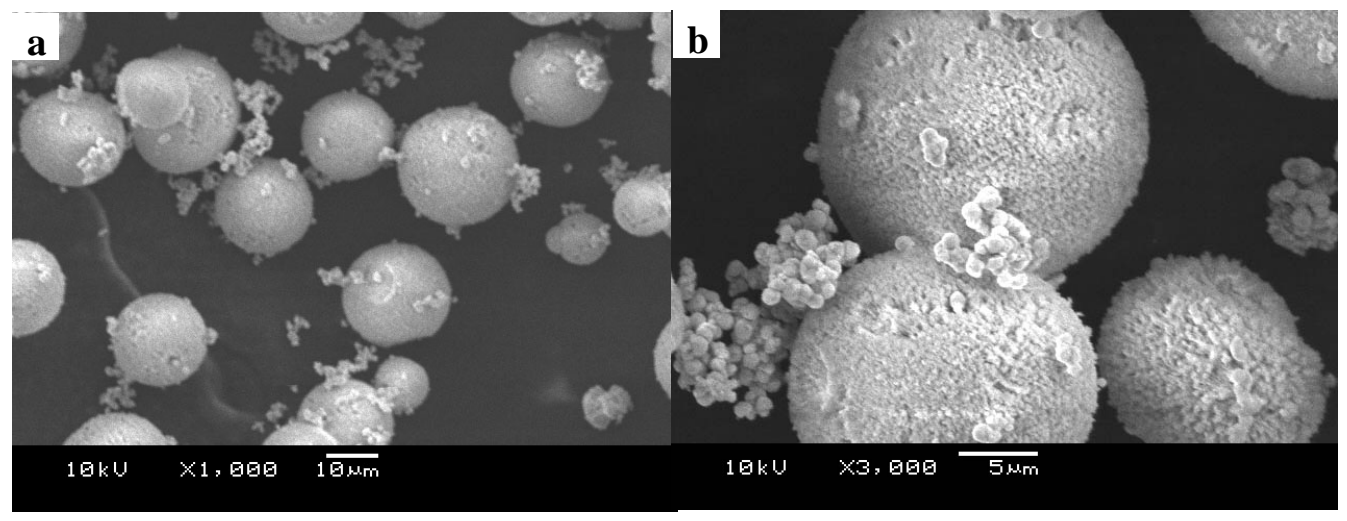

Figure S6. Malachite prepared at $110^{\circ} \mathrm{C}$ and $12 \mathrm{~h}$, the ethanol concentration of the initial solution is $20 \%$ (volume): (a) low magnification view; (b) high magnification view.

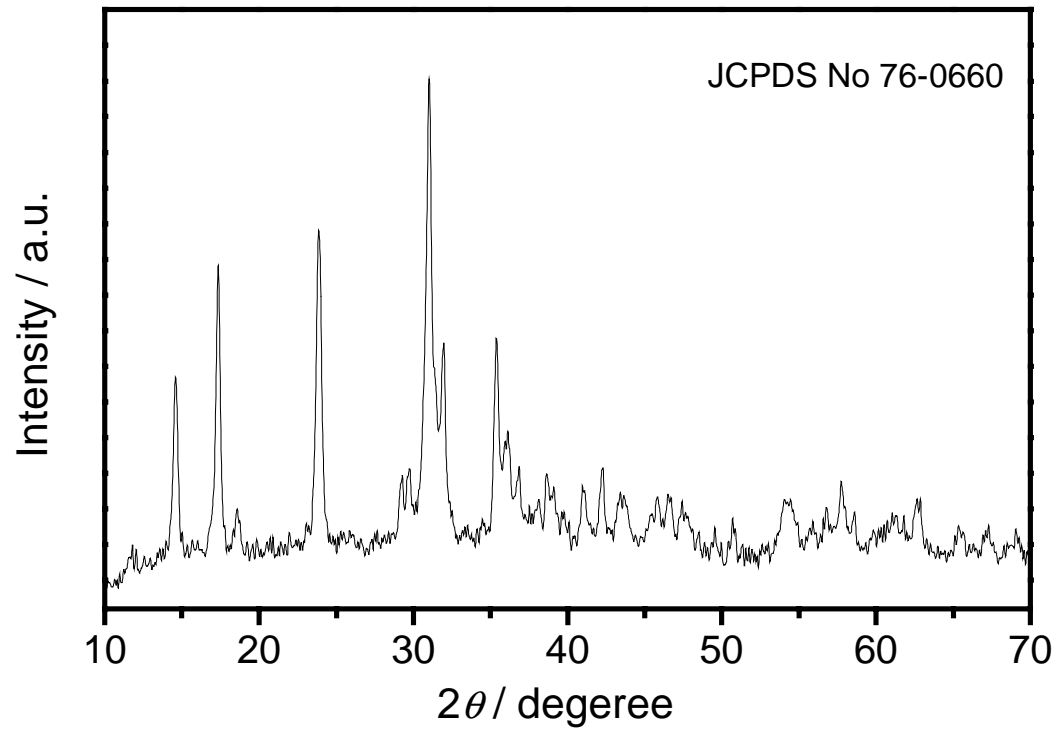

Figure S7. XRD patterns of malachite with the urchin-like morphology (prepared at $110^{\circ} \mathrm{C}$ and $12 \mathrm{~h}$, the concentration of initial $\mathrm{CuSO}_{4}$ and $\mathrm{K}_{2} \mathrm{CO}_{3}$ is $1.0 \mathrm{M}$ ) 


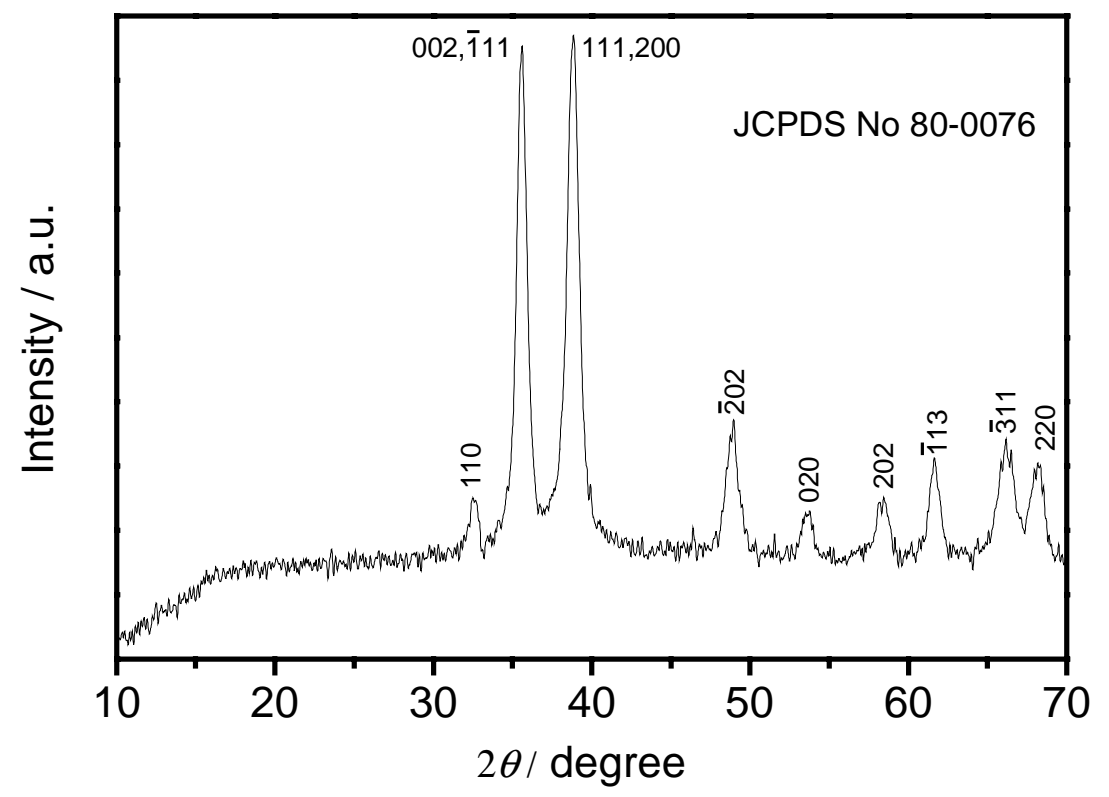

Figure S8. XRD patterns of $\mathrm{CuO}$ prepared at $180^{\circ} \mathrm{C}$ and $48 \mathrm{~h}$.

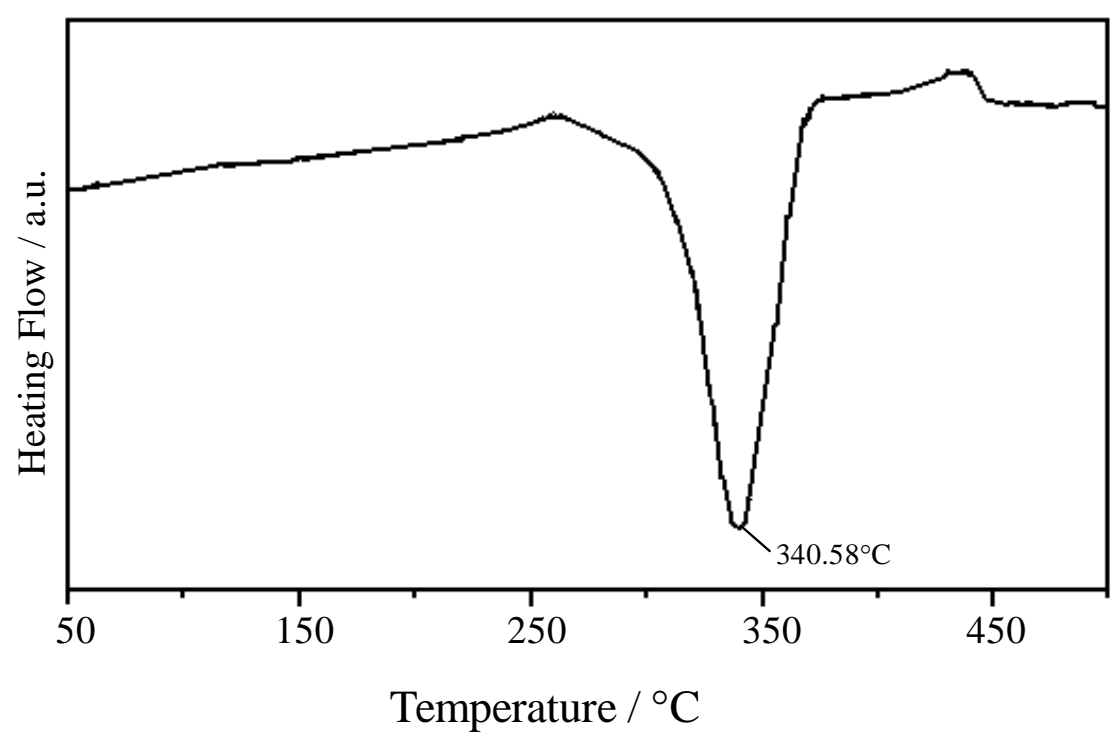

Figure S9. DSC analysis for malachite (prepared at $110^{\circ} \mathrm{C}$ and $12 \mathrm{~h}$ ) in a flowing air atmosphere. 


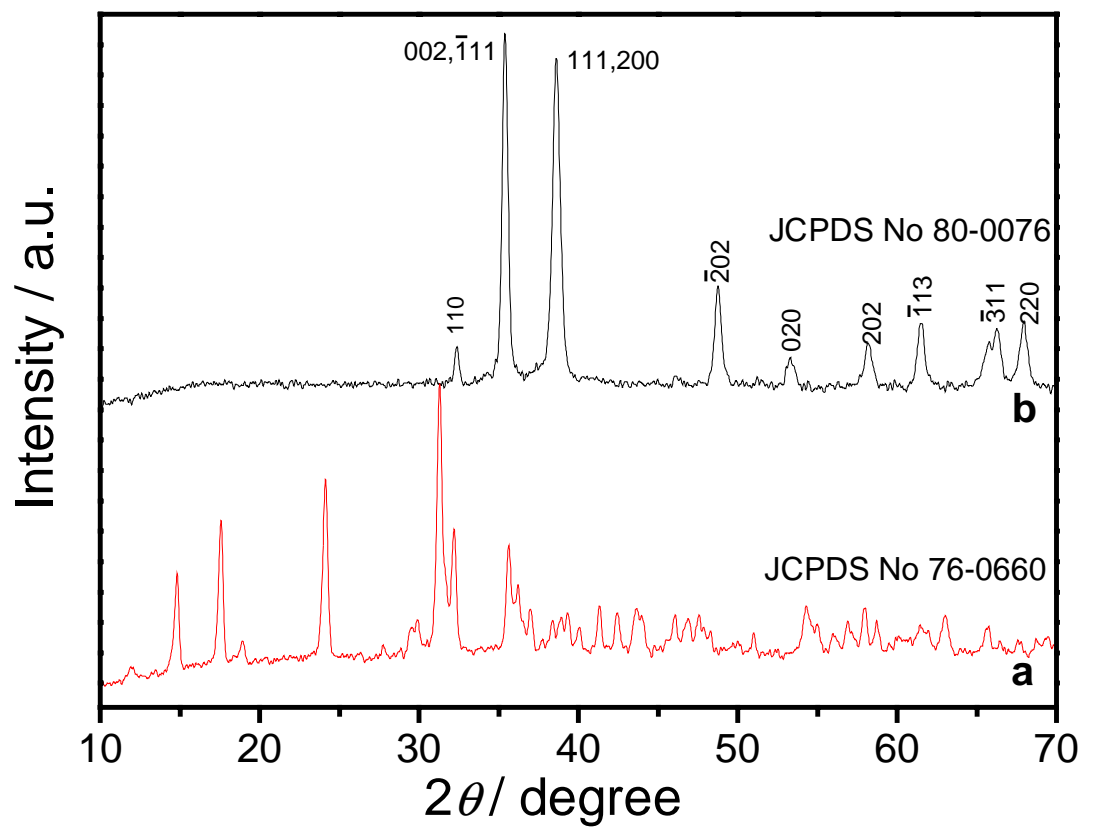

Figure S10. XRD patterns of samples: (a) malachite prepared at $110^{\circ} \mathrm{C}$ and $12 \mathrm{~h}$ (namely Figure 1); (b) $\mathrm{CuO}$ after the thermal treatment of malachite.

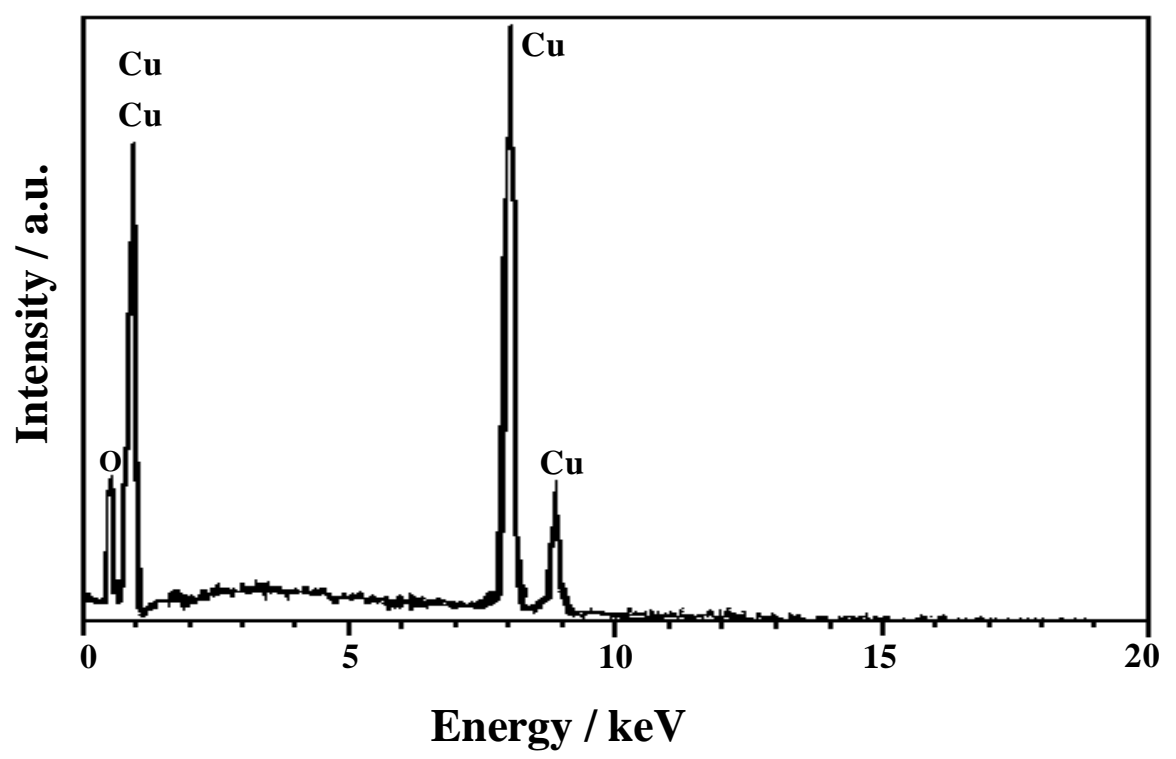

Figure S11. Energy-dispersive X-ray spectra of $\mathrm{CuO}$ after the thermal treatment of malachite. 